ARTICLE

https://doi.org/10.1038/s41467-020-15216-w

\title{
Interlayer gap widened $\alpha$-phase molybdenum trioxide as high-rate anodes for dual-ion- intercalation energy storage devices
}

\author{
Minghao Yu (1) 1,7, Hui Shao 2,3,7, Gang Wang (1) 1, Fan Yang ${ }^{4}$, Chaolun Liang5, Patrick Rozier (i) 2,3, \\ Cai-Zhuang Wang ${ }^{6}$, Xihong $\mathrm{Lu}^{4}$, Patrice Simon ${ }^{2,3 凶} \&$ Xinliang Feng (ib) ${ }^{1 凶}$
}

Employing high-rate ion-intercalation electrodes represents a feasible way to mitigate the inherent trade-off between energy density and power density for electrochemical energy storage devices, but efficient approaches to boost the charge-storage kinetics of electrodes are still needed. Here, we demonstrate a water-incorporation strategy to expand the interlayer gap of $\alpha$ $\mathrm{MoO}_{3}$, in which water molecules take the place of lattice oxygen of $\alpha-\mathrm{MoO}_{3}$. Accordingly, the modified $\alpha-\mathrm{MoO}_{3}$ electrode exhibits theoretical-value-close specific capacity $\left(963 \mathrm{Cg}^{-1}\right.$ at $0.1 \mathrm{mV} \mathrm{s}^{-1}$ ), greatly improved rate capability (from $4.4 \%$ to $40.2 \%$ at $100 \mathrm{mV} \mathrm{s}^{-1}$ ) and boosted cycling stability (from 21 to $71 \%$ over 600 cycles). A fast-kinetics dual-ion-intercalation energy storage device is further assembled by combining the modified $\alpha-\mathrm{MoO}_{3}$ anode with an anion-intercalation graphite cathode, operating well over a wide discharge rate range. Our study sheds light on a promising design strategy of layered materials for high-kinetics charge storage.

\footnotetext{
${ }^{1}$ Center for Advancing Electronics Dresden (cfaed) \& Department of Chemistry and Food Chemistry, Technische Universität Dresden, 01062 Dresden, Germany. ${ }^{2}$ CIRIMAT, Université de Toulouse, CNRS, Toulouse, France. ${ }^{3}$ Réseau sur le Stockage Electrochimique de I'Energie (RS2E), CNRS, 3459 Amiens, France. ${ }^{4} \mathrm{MOE}$ of the Key Laboratory of Bioinorganic and Synthetic Chemistry, The Key Lab of Low-carbon Chem \& Energy Conservation of Guangdong Province, KLGHEl of Environment and Energy Chemistry, School of Chemistry, Sun Yat-sen University, 510275 Guangzhou, China. ${ }^{5}$ Instrumental Analysis and Research Centre, Sun Yat-sen University, 510275 Guangzhou, China. ${ }^{6}$ Ames Laboratory-U. S. Department of Energy, and Department of Physics and Astronomy, lowa State University, Ames, IA 50011, USA. ${ }^{7}$ These authors contributed equally: Minghao Yu, Hui Shao. ${ }^{凶}$ email: simon@chimie.ups-tlse.fr; xinliang.feng@tu-dresden.de
} 
T riggered by a huge energy demand from various industries ranging from individual electronics to grid storage, electrochemical energy storage devices represent an active field for both research development and practical applications ${ }^{1-4}$. Typically, supercapacitors and batteries differ in electrochemical mechanisms, hence featuring almost opposite energy and power characteristics ${ }^{5-8}$. However, the demand for power and energy supply is equally imperative in actual use and is keen to expand in the future. Thus it is highly desirable to design new electrochemical energy storage technologies to mitigate the trade-off between power density and energy density ${ }^{9}$. Recently, the dualion energy storage (DIES) concept has attracted increasing attention as it holds different charge storage chemistry with the conventional "rocking-chair" mechanism ${ }^{10-13}$. In DIES devices, the electrolyte provides both cations and anions to be involved in charge storage. Graphitic carbon provides an ideal host for anion accommodation. The high anion-intercalating potential $(>4.0 \mathrm{~V}$ vs. $\mathrm{Li} / \mathrm{Li}^{+}$) and ultrafast rate capability ( $78 \%$ capacity retention, up to $100 \mathrm{C}$ rate) enable graphitic carbon a promising cathode for constructing energy storage devices with both high energy and power densities ${ }^{14}$. Previous studies have proposed several new DIES devices by assembling graphite cathode with conventional battery-type anodes (such as Li metal ${ }^{14}$, graphite ${ }^{15}, \mathrm{Al} \mathrm{metal}^{16}, \mathrm{Sn}$ metal ${ }^{17}, \mathrm{WS}_{2}{ }^{18}$, etc.). However, the power performance of DIES devices is still limited, and there is great interest in designing high-rate pseudocapacitive anode to be combined with graphite cathode to assemble high-energy, high-power DIES device.

Orthorhombic $\mathrm{MoO}_{3}\left(\alpha-\mathrm{MoO}_{3}\right)$ is composed of edge-sharing $\left[\mathrm{MoO}_{6}\right]$ octahedra bilayers stacked along [010] by van der Waals $(\mathrm{vdW})$ interaction. It has been considered as one of the most promising cation-intercalation materials due to its ecofriendliness and also high $\mathrm{Mo}^{6+} / \mathrm{Mo}^{4+}$ redox activity ${ }^{19,20}$. The $\mathrm{Li}^{+}$-intercalation reaction in $\alpha-\mathrm{MoO}_{3}$ involves both $\mathrm{Mo}^{6+} / \mathrm{Mo}^{5+}$ and $\mathrm{Mo}^{5+} / \mathrm{Mo}^{4+}$ redox couples, which makes $\mathrm{\alpha}-\mathrm{MoO}_{3}$ a promising electrode for Li-ion storage with a theoretical capacity of $1005 \mathrm{C} \mathrm{g}^{-121}$. Also, the electrochemical potential for Li-ion intercalation (around $2-3 \mathrm{~V}$ vs. $\mathrm{Li}^{\prime} \mathrm{Li}^{+}$) is far below the anionintercalation potential of graphitic carbon $\left(>4.0 \mathrm{~V}\right.$ vs. $\left.\mathrm{Li}^{2} / \mathrm{Li}^{+}\right)$, which suggests the promise for assembling DIES devices composed of $\mathrm{MoO}_{3}$ anode and graphite cathode. However, the widespread application of $\alpha-\mathrm{MoO}_{3}$ is severely restricted by its modest electrochemical reaction kinetics due to the low charge/ ion transport efficiency, leading to poor rate capability of $\alpha-\mathrm{MoO}_{3}$ electrodes ${ }^{19,22}$. In addition, the unfavorable phase transition of $a-$ $\mathrm{MoO}_{3}$ electrode around $2.8 \mathrm{~V}$ vs. $\mathrm{Li} / \mathrm{Li}^{+}$during the initial lithiation process results in the distortion of layers and a rapid capacity decay during the cycling test ${ }^{23,24}$. To tackle these obstacles, previous studies employed approaches like constructing nanostructures ${ }^{25}$ and creating oxygen vacancy ${ }^{26}$ to obtain favorable $\mathrm{\alpha}-\mathrm{MoO}_{3}$ electrode with pseudocapacitive charge storage behavior and acceptable cycling life. Nevertheless, those reported $\alpha-\mathrm{MoO}_{3}$ electrodes presented unsatisfied areal capacity performance due to low electrode weight loading (e.g., $39 \mathrm{mC} \mathrm{cm}^{-2}$ at 1 $\mathrm{mV} \mathrm{s}^{-1}$ with mass loading of $\left.40 \mathrm{\mu g} \mathrm{cm}^{-2}\right)^{26}$. Such low areal performance limits the practical interest of these electrodes in energy storage devices, since it would result in a drastic decrease in performance at the cell level27.

In this study, we widen the interlayer gaps of $\alpha-\mathrm{MoO}_{3}$ by incorporating $\mathrm{H}_{2} \mathrm{O}$ molecules between vdW interlayers $\left(\alpha-\mathrm{MoO}_{3}\right.$ with expanded interlayer gaps is denoted as $\left.\mathrm{e}-\mathrm{MoO}_{3}\right)$. The incorporated $\mathrm{H}_{2} \mathrm{O}$ molecules take the place of lattice $\mathrm{O}$ of $\alpha$ $\mathrm{MoO}_{3}$ and expand the ionic channel dimension, which is evidenced by the obviously increased $b$-lattice parameter of e$\mathrm{MoO}_{3}(15.02 \AA)$ compared to $\alpha-\mathrm{MoO}_{3}(13.85 \AA)$. e- $-\mathrm{MoO}_{3}$ electrode prepared from this approach exhibits a high specific capacity $\left(963 \mathrm{C} \mathrm{g}^{-1}\right.$ or $578 \mathrm{mC} \mathrm{cm}^{-2}$ at $0.1 \mathrm{mV} \mathrm{s}^{-1}$ ), remarkably improved electrochemical reaction kinetics with boosted rate performance $\left(\mathrm{e}-\mathrm{MoO}_{3}\right.$ vs. $\alpha-\mathrm{MoO}_{3}: 40.2 \%$ vs. $4.4 \%$ capacity retention at $\left.100 \mathrm{mV} \mathrm{s}^{-1}\right)$ as well as cycling life (e- $-\mathrm{MoO}_{3}$ vs. $\alpha-\mathrm{MoO}_{3}: 71 \%$ vs. $21 \%$ capacity retention over 600 cycles) during $\mathrm{Li}^{+}$storage. Finally, we assemble a DIES device combining a $\mathrm{Li}^{+}$-intercalation e- $\mathrm{MoO}_{3}$ anode together with $\mathrm{a} \mathrm{PF}_{6}{ }^{-}$-intercalation graphite cathode in $2 \mathrm{M} \mathrm{LiPF}_{6}$ electrolyte. Taking advantage of the fast-kinetics intercalation/de-intercalation processes at both anode and cathode, the as-assembled DIES device operates within a 1.0-3.5 $\mathrm{V}$ voltage window over a wide discharge rate range (discharge time from $25 \mathrm{~s}$ to $3.5 \mathrm{~h}$ ), and shows high energy density (up to $44 \mathrm{Wh} \mathrm{L}^{-1}$ based on the whole device) with decent power capability $\left(600 \mathrm{~W} \mathrm{~L}^{-1}\right)$.

\section{Results}

Expanding the interlayer gaps of $\mathbf{a}-\mathrm{MoO}_{3}$. The procedure for expanding interlayer gaps of pristine $\mathrm{a}-\mathrm{MoO}_{3}$ is described in Fig. 1a. $a-\mathrm{MoO}_{3}$ nanowires were first synthesized through a hydrothermal method and further immersed for $12 \mathrm{~h}$ in a solution of $n$-butyllithium dissolved in hexane. Fast color change from white to dark blue was observed (Fig. 1b), suggesting the creation of reduced Mo species due to $\mathrm{Li}^{+}$intercalation ${ }^{19,26}$. Afterwards, the sample was transferred into water, resulting in the oxidation of the sample by $\mathrm{Li}^{+}$removal and simultaneous reduction of water into gaseous hydrogen. Thus the combination of reduction using $n$-butyllithium and oxidation using $\mathrm{H}_{2} \mathrm{O}$ leads to a complex process enlisting also a replacement of lattice oxygen by some $\mathrm{H}_{2} \mathrm{O}$ molecules, which enforces the expansion of the interlayer gaps.

The comparison of X-ray diffraction (XRD) patterns confirms the expansion of the interlayer space. The diffraction data of pristine $\alpha-\mathrm{MoO}_{3}$ (Supplementary Fig. 1 and Supplementary Note 1) are indexed to JCPDS card no. 05-0508. It crystallizes in the orthorhombic system (SG: Pbnm) with the refined lattice parameters of $a=3.96$ (6) $\AA, b=13.85$ (1) $\AA, c=3.70$ (5) $\AA$. e$\mathrm{MoO}_{3}$ maintains similar peaks of $\alpha-\mathrm{MoO}_{3}$ with relatively broad peak width and, more importantly, shows $(0 k 0)$ peaks shifted toward lower angles (Fig. 1c). These peaks refer to an enlarged $b$ value of 15.02 (3) $\AA$, while $a$ and $c$ parameters stay almost unchanged ( $a=4.08$ (3) $\AA, c=3.75$ (2) $\AA$ ). This result indicates an impressive expansion of the interlayer distance by $0.6 \AA$, largely higher than the $0.1 \AA$ expansion reported for oxygen deficient $\alpha-\mathrm{MoO}_{3}$ compound ${ }^{26}$. Thus the wide interlayer distance in e- $\mathrm{MoO}_{3}$ reported here is far above the interlayer distance solely induced by the oxygen vacancies. High-resolution transmission electron microscopic (TEM) and scanning electron microscopic (SEM) images (Fig. 1d and Supplementary Fig. 2) confirm that e$\mathrm{MoO}_{3}$ retains the nanowire structure but with a rougher surface with numerous cracks, in agreement with mechanical strains induced by the large expansion of interlayer space.

To elucidate the composition evolution along with interlayer gap expansion, Fourier transform infrared (FTIR) and Raman measurements have been conducted for $\alpha-\mathrm{MoO}_{3}$ and e- $\mathrm{MoO}_{3}$ (Supplementary Fig. 3 and Supplementary Note 2). Compared with the FTIR and Raman peaks of $\mathrm{MoO}_{3}$, the remarkable change observed for $\mathrm{e}-\mathrm{MoO}_{3}$ indicates the obvious crystal rearrangement of the $\left[\mathrm{MoO}_{6}\right]$ octahedra bilayers in e- $\mathrm{MoO}_{3}$. Electron paramagnetic resonance (EPR) spectra of both $\alpha-\mathrm{MoO}_{3}$ and $\mathrm{e}-\mathrm{MoO}_{3}$ were measured at a low temperature of $90 \mathrm{~K}$ (Supplementary Fig. 4). In contrast to $\alpha-\mathrm{MoO}_{3}, \mathrm{e}-\mathrm{MoO}_{3}$ displays an apparent signal with a $g$ value of 1.93 and a line width of 49 Gs, which can be assigned to the presence of $\mathrm{Mo}^{5+}$ donor levels close to the conduction band ${ }^{28,29}$. Consistent result is identified in Mo 3d X-ray photoelectron spectroscopy (XPS) data of e- $\mathrm{MoO}_{3}$ with newly appeared $\mathrm{Mo}^{5+} 3 \mathrm{~d} 3 / 2$ and $3 \mathrm{~d} 5 / 2$ peaks (234.7 and 


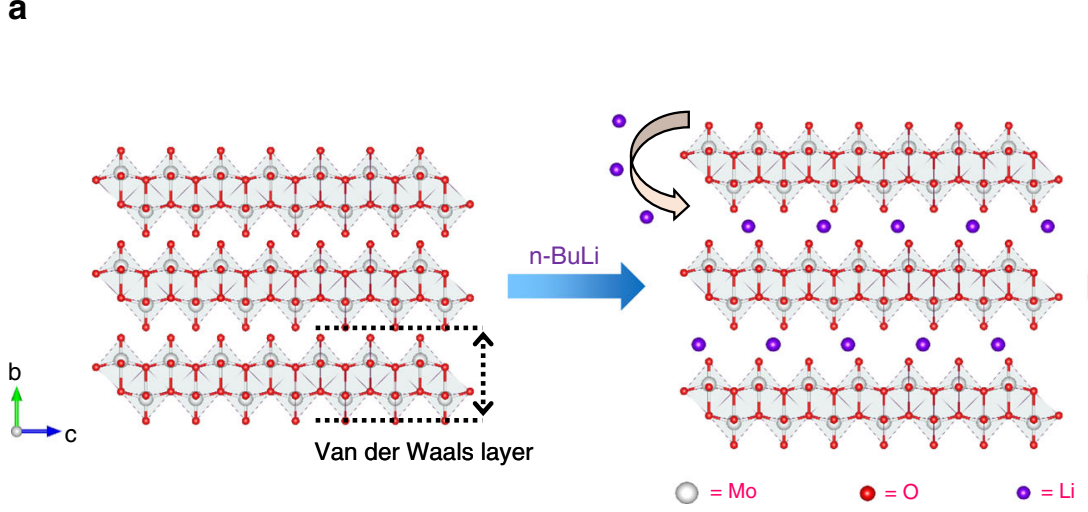

b
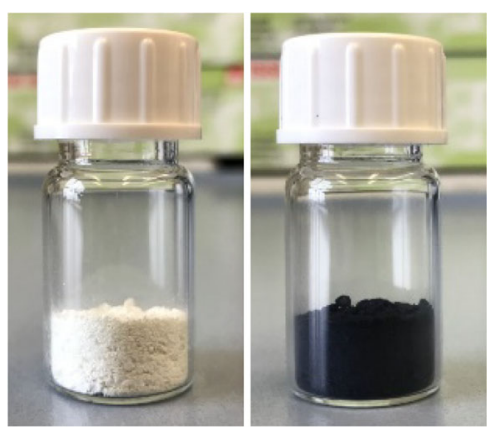

c

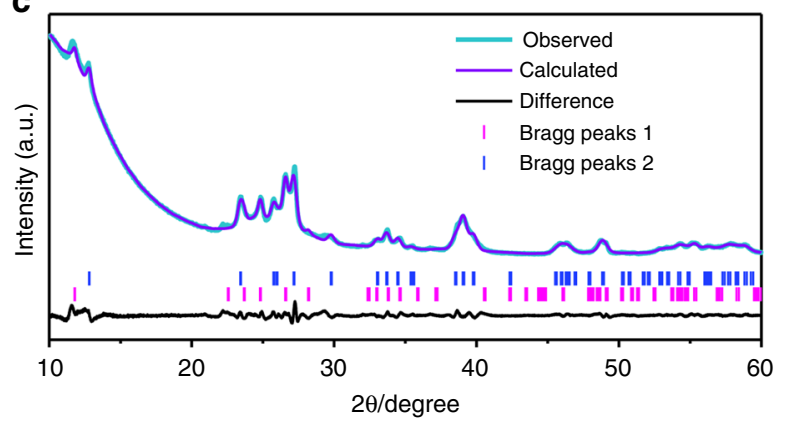

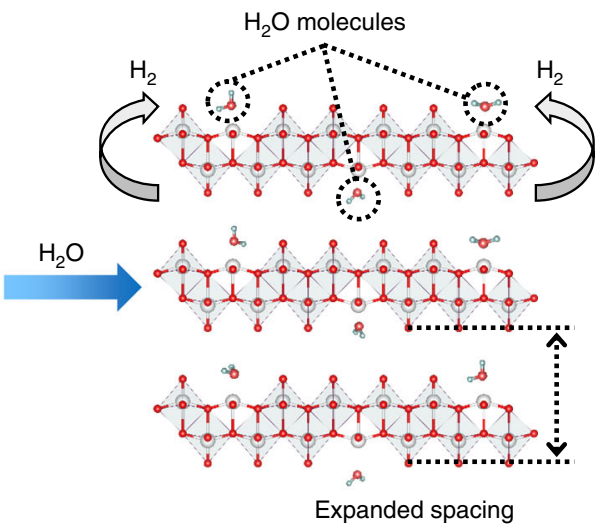

d

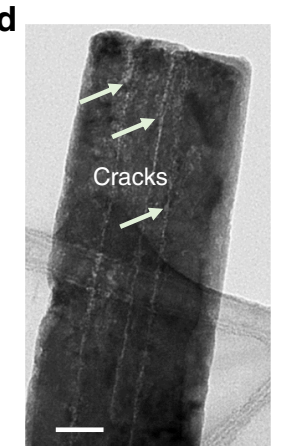

e

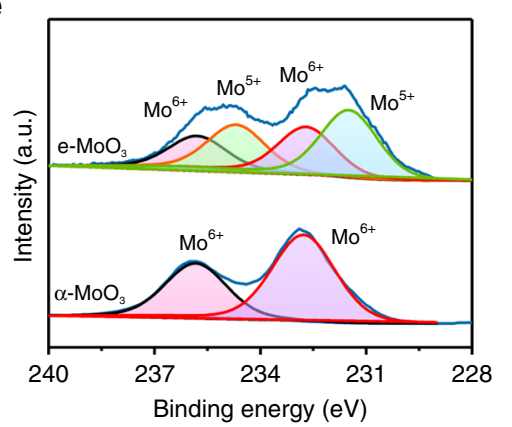

f

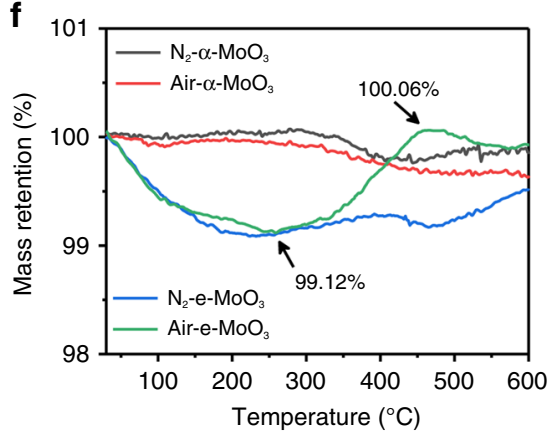

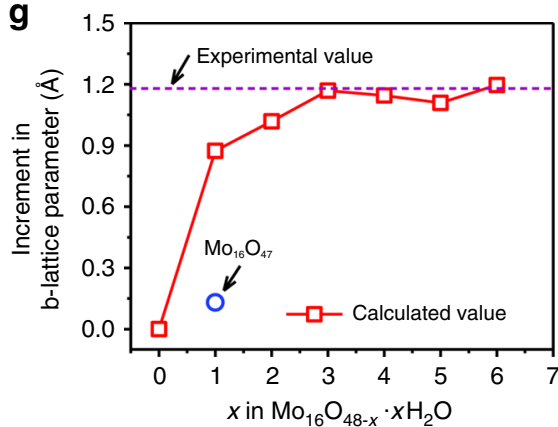

Fig. 1 Structure and composition analysis of $\mathbf{\alpha}-\mathbf{M o O}_{\mathbf{3}}$ and $\mathbf{e}-\mathbf{M o O}_{3}$. a Schematic representation of expansion process from pristine $\alpha-\mathrm{MoO}{ }_{3}$ (left), reaction with $n$-butyllithium (middle), to e- $\mathrm{MoO}_{3}$ with $\mathrm{H}_{2} \mathrm{O}$ molecules located at the oxygen-defect sites (right). White: Mo; Red: O; Purple: Li; Blue: $\mathrm{H}$. b Digital photos of $\alpha-\mathrm{MoO}_{3}$ (left) and e- $\mathrm{MoO}_{3}$ (right). c Rietveld refinement of XRD pattern and $\mathbf{d}$ high-resolution TEM image for e-MoO .Scale bar in $\mathbf{d} 50 \mathrm{~nm}$. e Mo $3 d$ XPS profiles of $\alpha-\mathrm{MoO}_{3}$ and e- $-\mathrm{MoO}_{3}$. f TGA curves of $\alpha-\mathrm{MoO}_{3}$ and e- $\mathrm{MoO}_{3}$ measured in nitrogen and air atmosphere. $\mathbf{g}$ Calculated increment in $b$ lattice parameter induced by $\mathrm{H}_{2} \mathrm{O}$ intercalation. The value is also compared with the calculated value of oxygen-defective $\mathrm{MoO}_{3-x}\left(\mathrm{Mo}_{16} \mathrm{O}_{47}\right)$ and experimental value.

$231.5 \mathrm{eV}$, respectively, Fig. 1e $)^{19,26}$. The atomic ratio between $\mathrm{Mo}^{5+}$ and $\mathrm{Mo}^{6+}$ reaches approximately 3:2. Comparison of $\mathrm{O} 1 \mathrm{~s}$ XPS spectra (Supplementary Fig. 5) shows the presence of an extra peak at $532.4 \mathrm{eV}$ for $\mathrm{e}-\mathrm{MoO}_{3}$ in addition to the peak located at $530.7 \mathrm{eV}$ observed in $\alpha-\mathrm{MoO}_{3}$ which is characteristic of lattice oxygen $^{30}$. This confirms the presence of incorporated $\mathrm{H}_{2} \mathrm{O}$ in e$\mathrm{MoO}_{3}$ sample, and the atomic percentage of $\mathrm{O}$ in the incorporated $\mathrm{H}_{2} \mathrm{O}$ accounts for about $10 \%$ of total $\mathrm{O}$ atoms. No $\mathrm{Li} 1 \mathrm{~s}$ signal is detected for e- $\mathrm{MoO}_{3}$, ruling out the possible prelithiation in e- $\mathrm{MoO}_{3}$ (Supplementary Fig. 6). This is consistent with the XRD patterns of e- $\mathrm{MoO}_{3}$ after annealing in either $\mathrm{N}_{2}$ or air, where no Li-containing compound is observed (Supplementary Fig. 7 and Supplementary Note 3). Thus, based on XPS analyses, the surface composition of $\mathrm{e}-\mathrm{MoO}_{3}$ can be roughly estimated as $\mathrm{MoO}_{2.7} \cdot 0.3 \mathrm{H}_{2} \mathrm{O}$. Thermogravimetry analysis (TGA, Fig. 1f) of $\mathrm{e}-\mathrm{MoO}_{3}$ in the air was conducted to estimate the amount of incorporated $\mathrm{H}_{2} \mathrm{O}$ in the whole sample. It presents the loss of intercalated water occurring at $\sim 250{ }^{\circ} \mathrm{C}$ (mass retention of $99.12 \%$ ) and the re-oxidation of oxygen-deficient $\mathrm{MoO}_{3}$ in the temperature range of $250-460{ }^{\circ} \mathrm{C}$ (mass retention of $100.06 \%$ ), which is indicative of the formula $\mathrm{MoO}_{2.92} \cdot 0.07 \mathrm{H}_{2} \mathrm{O}$ for $\mathrm{e}-\mathrm{MoO}_{3}$. From both XPS and TGA analysis, we notice that the molar amount of oxygen defects is approximately equal to that of the incorporated $\mathrm{H}_{2} \mathrm{O}$ molecules. Thus we consider that the incorporated $\mathrm{H}_{2} \mathrm{O}$ molecules take the place of lattice $\mathrm{O}$ of e- $\mathrm{MoO}_{3}$, functioning as buffered spacer to stabilize the widened interlayer gaps between the layers. This assumption is further supported by the density functional theory (DFT) simulation, which is performed employing the bulk supercells of $\mathrm{Mo}_{16} \mathrm{O}_{48-x} \cdot x \mathrm{H}_{2} \mathrm{O}(x=1-6$, which represents the number of the incorporated $\mathrm{H}_{2} \mathrm{O}$ molecules) shown in Supplementary Figs. 8 and 9. Notably, an increment of $0.9 \AA$ in the $b$-lattice parameter is revealed even when one lattice $\mathrm{O}$ is replaced by one $\mathrm{H}_{2} \mathrm{O}$ molecule (Fig. 1g). By contrast, for the sample with only oxygen defects $\left(\mathrm{Mo}_{16} \mathrm{O}_{47}\right)$, the increment can 
only reach $0.13 \AA$, which further confirms the dominant role of the incorporated $\mathrm{H}_{2} \mathrm{O}$ in expanding the interlayer gaps. When $x$ is between 3 and 6 (corresponding to $\mathrm{MoO}_{2.81} \cdot 0.19 \quad \mathrm{H}_{2} \mathrm{O}$ to $\mathrm{MoO}_{2.63} \cdot 0.37 \mathrm{H}_{2} \mathrm{O}$ ), the calculated increment in the $b$-lattice parameter agrees well with our experimental XRD results. In addition, the simulated $\mathrm{e}-\mathrm{MoO}_{3}$ structure with most stable configuration also reveals that the incorporated $\mathrm{H}_{2} \mathrm{O}$ induces the distortion of the $\left[\mathrm{MoO}_{6}\right]$ octahedra (Supplementary Fig. 10), leading to substantial changes in $\mathrm{O}-\mathrm{O}$ distances (both intra- and inter-layer ones, Supplementary Fig. 11 and Supplementary Note 4).

The increment in band density near the Fermi level for e$\mathrm{MoO}_{3}$ compared with $\alpha-\mathrm{MoO}_{3}$ is evidenced by the ultraviolet photoelectron spectroscopy analysis (Supplementary Figs. 12 and 13 and Supplementary Note 5) and O K-edge X-ray absorption near-edge structure spectra (Supplementary Fig. 14 and Supplementary Note 6). e- $\mathrm{MoO}_{3}$ sample exhibits a remarkable conductivity of $0.95 \mathrm{~S} \mathrm{~m}^{-1}$ at $300 \mathrm{~K}$ as determined by the van der Pauw 4-probe method (Supplementary Fig. 15), whereas the conductivity of pristine $\alpha-\mathrm{MoO}_{3}$ was too low to be detected. The enhanced conductivity can be explained by the narrowed band gap and the increment in the carrier concentration (Supplementary Fig. 16 and Supplementary Note 7), which can be attributed to the electron hopping mechanism boosted by $\mathrm{Mo}^{5+31,32}$.

Enhanced $\mathrm{Li}^{+}$storage kinetics of e- $\mathrm{MoO}_{3}$. e- $\mathrm{MoO}_{3}$ sample with large opened interlayer space has been used as electrode material for $\mathrm{Li}$-ion intercalation reaction. Figure $2 \mathrm{a}, \mathrm{b}$ compares the initial three galvanostatic charge/discharge cycles at $50 \mathrm{mAg}^{-1}$ in $2 \mathrm{M} \mathrm{LiPF}_{6}$ dissolved in ethyl methyl carbonate electrolyte. The first lithiation process of $\alpha-\mathrm{MoO}_{3}$ starts with a short constant potential plateau at about $2.75 \mathrm{~V}$ vs. $\mathrm{Li} / \mathrm{Li}^{+}$, which is consistent with the presence of a reduction peak in the first cathodic cyclic voltammetry $(\mathrm{CV})$ cycle (Supplementary Fig. 17). This process is related to an irreversible phase transition and will be later discussed in more detail in the in operando XRD section. By contrast, such a feature is not observed in the first lithiation reaction of e- $\mathrm{MoO}_{3}$, identifying the role of the widened interlayer gaps in inhibiting the phase transition. Also, the Coulombic efficiency of e- $\mathrm{MoO}_{3}$ in the first cycle (85\%) is found to be higher than that of $\alpha-\mathrm{MoO}_{3}$ (78\%). Such an improvement is also observed during the next cycles (Fig. 2a, b).

$\mathrm{CV}$ curves from a scan rate range of $0.1-100 \mathrm{mV} \mathrm{s}^{-1}$ were collected for both $\mathrm{a}-\mathrm{MoO}_{3}$ and e- $\mathrm{MoO}_{3}$ electrodes with similar weight loadings (Supplementary Fig. 18). As revealed in Fig. 2c, e$\mathrm{MoO}_{3}$ depicts both higher capacity and better rate capability than $\alpha-\mathrm{MoO}_{3}$. At an extremely slow scan rate of $0.1 \mathrm{mV} \mathrm{s}^{-1}$, the capacity of e- $\mathrm{MoO}_{3}$ electrode is close to the theoretical capacity $\left(1005 \mathrm{C} \mathrm{g}^{-1}\right.$, $279 \mathrm{mAh} \mathrm{g}^{-1}$ ), while $\mathrm{a}-\mathrm{MoO}_{3}$ electrode only shows a capacity of $756 \mathrm{C} \mathrm{g}^{-1}$ (210 $\left.\mathrm{mAh} \mathrm{g}^{-1}\right)$. Importantly, our e- $\mathrm{MoO}_{3}$ electrode delivers an outstanding areal capacity of $578 \mathrm{mC} \mathrm{cm}^{-2}$, drastically outperforming the reported state-of-the-art $\alpha-\mathrm{MoO}_{3}$-based pseudocapacitive electrodes $19,22,25,26,33$. When the scan rate increases to 10 and $100 \mathrm{mV} \mathrm{s}^{-1}, \mathrm{e}-\mathrm{MoO}_{3}$ can maintain high capacities of 233 and $72 \mathrm{mC} \mathrm{cm}^{-2}$, respectively, indicating high power capability. As for $\mathrm{a}-\mathrm{MoO}_{3}$ electrode, the capacity at 10 and $100 \mathrm{mV} \mathrm{s}^{-1}$ can only reach 20 and $3 \mathrm{mC} \mathrm{cm}^{-2}$, respectively. Moreover, galvanostatic charge/discharge profiles at different rates also verify the superior rate capability of e- $\mathrm{MoO}_{3}$ electrode (Supplementary Fig. 19).

The significant role of the incorporated $\mathrm{H}_{2} \mathrm{O}$ molecules in accelerating the diffusion of $\mathrm{Li}^{+}$within e- $\mathrm{MoO}_{3}$ lattice was further studied. Figure $2 \mathrm{~d}$ compares the $\mathrm{Li}^{+}$diffusion coefficient $(D)$ of $\alpha$ $\mathrm{MoO}_{3}$ and $\mathrm{e}-\mathrm{MoO}_{3}$ obtained by employing a galvanostatic intermittent titration technique (GITT, see Supplementary Figs. 20 and 21). The $D_{\mathrm{Li}+}$ values in e- $\mathrm{MoO}_{3}$ electrode $\left(2.4 \times 10^{-12}-3.5 \times\right.$ $10^{-10} \mathrm{~cm}^{2} \mathrm{~s}^{-1}$ ) are substantially higher than those in $\alpha-\mathrm{MoO}_{3}$ electrode $\left(3.9 \times 10^{-13}-6.0 \times 10^{-11} \mathrm{~cm}^{2} \mathrm{~s}^{-1}\right)$. The fastened $\mathrm{Li}^{+}$ diffusion can be assigned to both the expanded ionic diffusion channels and the shielding effect of incorporated $\mathrm{H}_{2} \mathrm{O}$ that screens the electrostatic interaction between $\mathrm{Li}^{+}$and $\mathrm{MoO}_{3}$ lattice ${ }^{34,35}$. Meanwhile, we measured the electrochemical impedance spectroscopy for both $\mathrm{a}-\mathrm{MoO}_{3}$ (Supplementary Fig. 22) and e- $\mathrm{MoO}_{3}$ (Fig. 2e) at various potentials from the cathodic process. Both electrodes depict stable ohmic resistance $\left(R_{\mathrm{s}}\right)$ and $\mathrm{V}$-shape variation for charge transfer resistance $\left(R_{\mathrm{ct}}\right)$ along with the change of potential (Supplementary Fig. 23). It can be observed that $R_{s}, R_{\mathrm{ct}}$, and the overall resistance of e- $\mathrm{MoO}_{3}$ are all lower than those of $\alpha$ $\mathrm{MoO}_{3}$, further justifying the improved charge and ion transfer efficiency for e- $\mathrm{MoO}_{3}$.
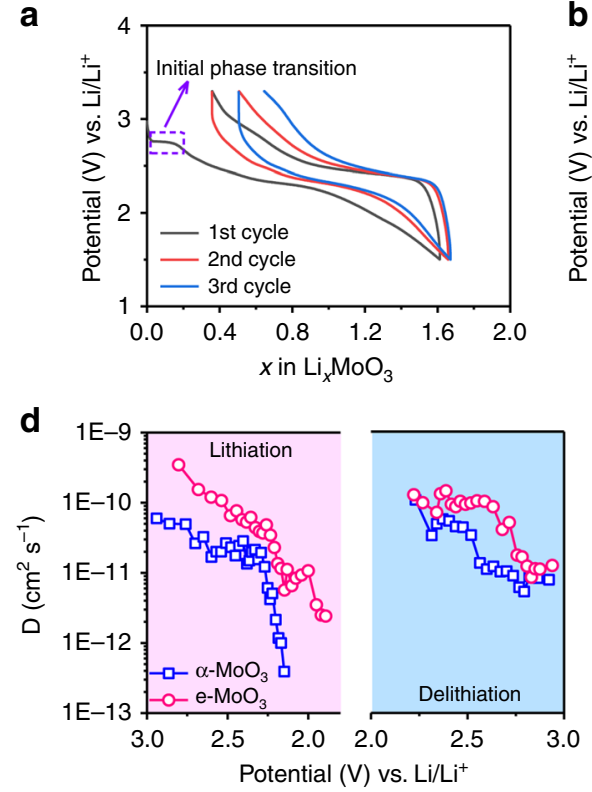
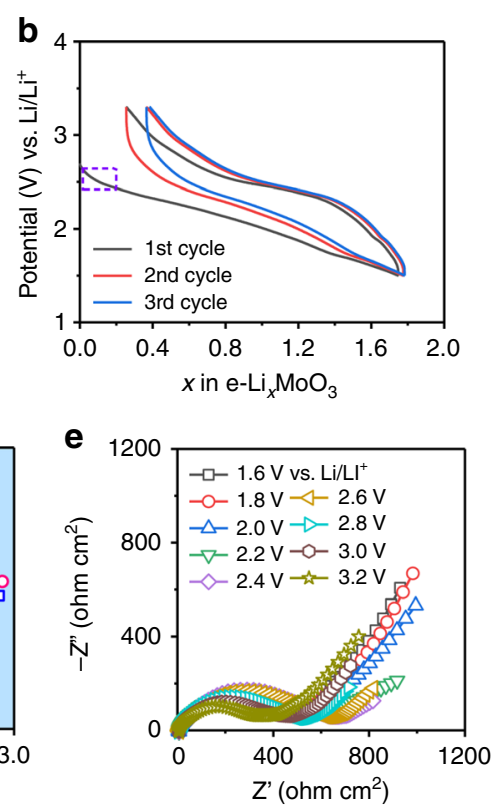
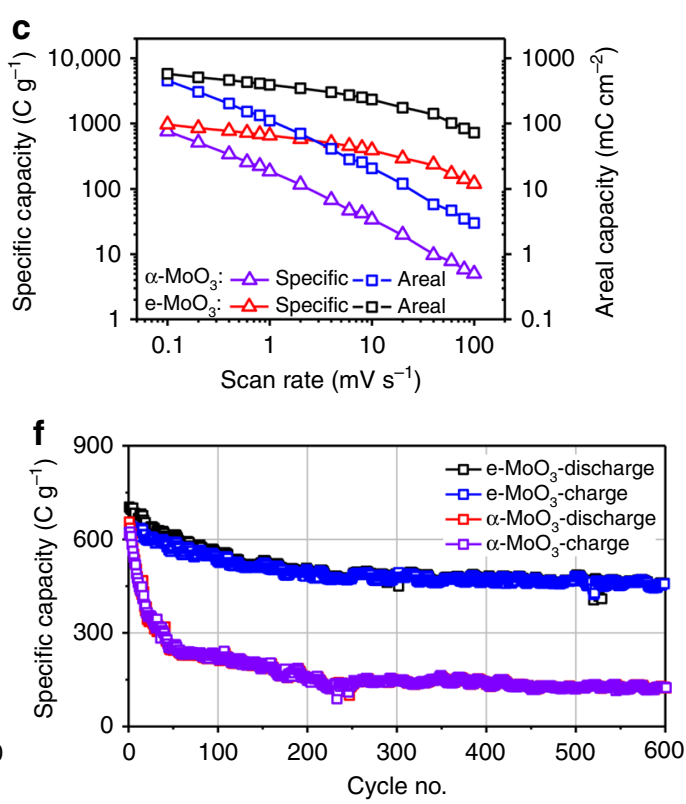

Fig. $2 \mathbf{~ L i}^{+}$storage behavior of $\boldsymbol{\alpha}-\mathbf{M o O}_{\mathbf{3}}$ and $\mathbf{e}-\mathbf{M o O}_{\mathbf{3}}$ electrodes. Initial three galvanostatic charge/discharge profiles of a $\alpha-M o \mathrm{O}_{3}$ and $\mathbf{b}$ e- $\mathrm{MoO}$ electrodes. c Specific and areal capacity as a function of scan rate. d $\mathrm{Li}^{+}$diffusion coefficient calculated from $\mathrm{GITT}$ curves. e $\mathrm{Nyquist}$ plots of e-MoO $\mathrm{O}_{3}$ at different potentials. $\mathbf{f}$ Cycling performance of $\alpha-\mathrm{MoO}_{3}$ and e- $\mathrm{MoO}_{3}$ at $100 \mathrm{~mA} \mathrm{~g}{ }^{-1}$. 

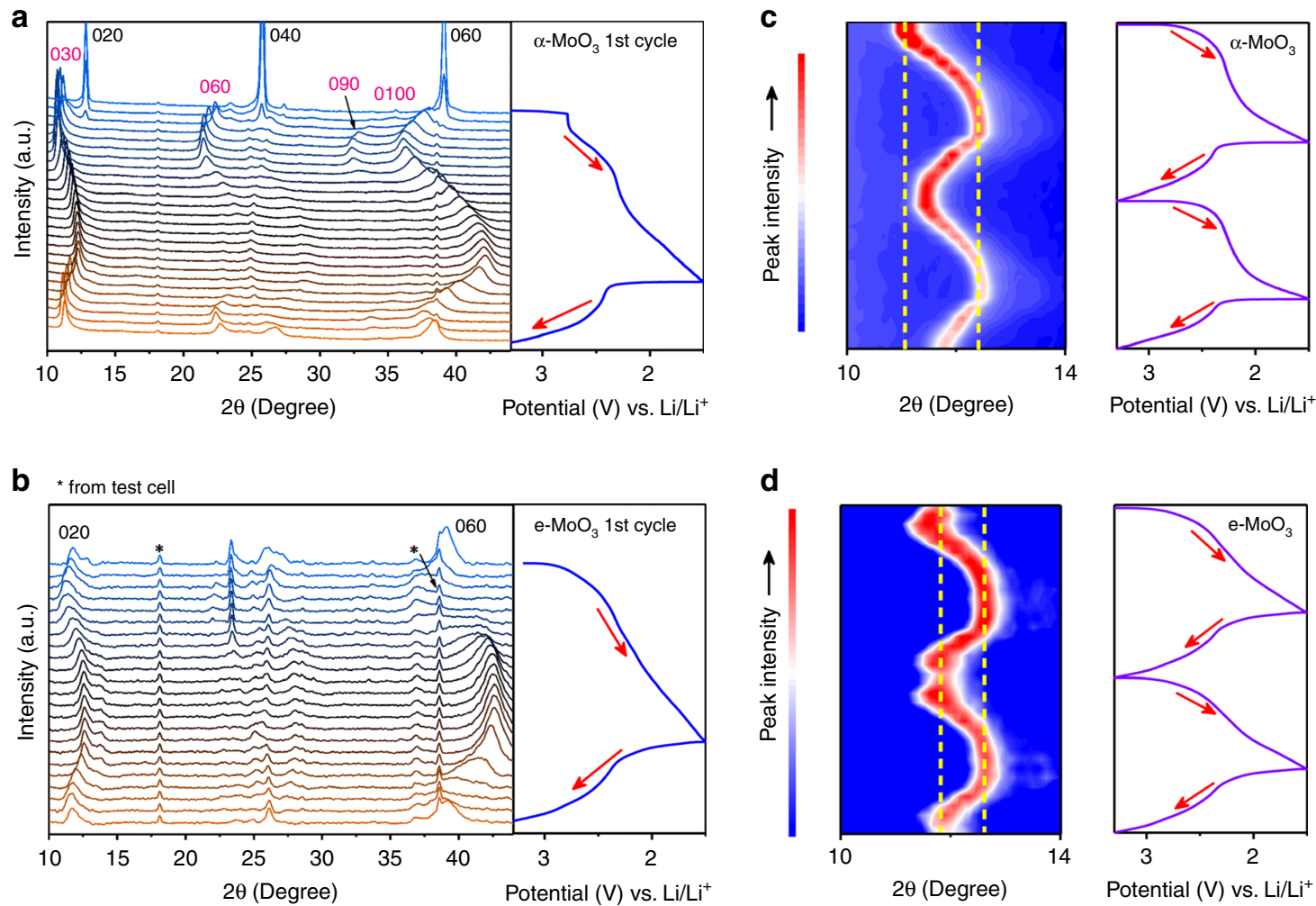

Fig. 3 In operando XRD study. In operando XRD measurements of $\mathbf{a}, \mathbf{c} \alpha-\mathrm{MoO}_{3}$ and $\mathbf{b}, \mathbf{d}$ e- $-\mathrm{MoO}_{3}$ electrodes during $\mathbf{a}$, $\mathbf{b}$ the first galvanostatic lithiation/delithiation cycle and $\mathbf{c}, \mathbf{d}$ the second and third cycles.

In addition, $\mathrm{e}-\mathrm{MoO}_{3}$ electrode exhibits a significant improvement in cycling stability compared to $\alpha-\mathrm{MoO}_{3}$ (Fig. 2f). When cycled at $100 \mathrm{~mA} \mathrm{~g}^{-1}$ for 600 cycles, e- $\mathrm{MoO}_{3}$ still maintains a high capacity of $455 \mathrm{Cg}^{-1}$, delivering excellent capacity retention of $71 \%$. In contrast, $\alpha-\mathrm{MoO}_{3}$ electrode shows rapid capacity decay, from $586 \mathrm{C}$ $\mathrm{g}^{-1}$ in the first cycle to $175 \mathrm{C} \mathrm{g}^{-1}$ after only 50 cycles.

To gain insight into the performance superiority of e- $\mathrm{MoO}_{3}$ to pristine $\mathrm{a}-\mathrm{MoO}_{3}$, we further carried out in operando XRD characterizations of electrodes during the first three lithiation/delithiation cycles. During the initial lithiation (Fig. 3a), $\alpha-\mathrm{MoO}_{3}$ electrode experienced an irreversible phase transition at $2.75 \mathrm{~V}$ vs. $\mathrm{Li} / \mathrm{Li}^{+}$, which was evidenced by the rapid disappearance of the $\left(0 k_{1} 0\right)$ peaks of the pristine $\alpha-\mathrm{MoO}_{3}$ and the appearance of a set of broad $\left(0 k_{2} 0\right)$ peaks belonging to the lithiated $\mathrm{MoO}_{3}\left(\mathrm{Li}_{x} \mathrm{MoO}_{3}\right)$. This irreversible phase transition results in a sudden distortion of the layers in $\alpha-\mathrm{MoO}_{3}$, which accounts for the fast structural collapse and sluggish kinetics of $\alpha-\mathrm{MoO}_{3}{ }^{36}$. Although limited information can be gained for e- $\mathrm{MoO}_{3}$ from XRD peaks within $15-35^{\circ}$ due to the overlap of multiple peaks, one can clearly notice that the primitive (020) and (060) peaks of e- $\mathrm{MoO}_{3}$ were well maintained during the whole lithiation/de-lithiation process (Fig. 3b). This result suggests a stable structural phase resulting from the expanded interlayer gaps in e- $\mathrm{MoO}_{3}$. We further compare the shift of the $(0 k 0)$ peak of $\alpha-\mathrm{MoO}_{3}$ and e- $-\mathrm{MoO}_{3}$ located between $10^{\circ}$ and $14^{\circ}$ during the second and third lithiation/de-lithiation cycles (Fig. 3c, d), which is directly associated with the volume change of the lattice in $b$ direction. Benefiting from the lessened electrostatic interaction between $\mathrm{Li}^{+}$and $\mathrm{MoO}_{3}$ lattice, the peak shift of e- $\mathrm{MoO}_{3}\left(0.8^{\circ}\right)$ during the second cycle is apparently smaller than that of $\mathrm{a}-\mathrm{MoO}_{3}$ $\left(1.3^{\circ}\right)$. Besides, almost no difference is observed between the peaks of e- $\mathrm{MoO}_{3}$ at the beginning of the second cycle and at the end of the third cycle, while $\alpha-\mathrm{MoO}_{3}$ displays a peak shift of $0.6^{\circ}$. Thus we conclude that the incorporated $\mathrm{H}_{2} \mathrm{O}$ molecules efficiently alleviate the volume change of $\mathrm{e}-\mathrm{MoO}_{3}$ and prevent the structure collapse during $\mathrm{Li}^{+}$insertion/extraction, which also explains the enhanced cycling performance of e- $\mathrm{MoO}_{3}$ with respect to $\alpha-\mathrm{MoO}_{3}$. Moreover, aside from $\alpha-\mathrm{MoO}_{3}$, we also demonstrated the feasibility of our $\mathrm{H}_{2} \mathrm{O}$-incorporation strategy in improving the charge storage ability of birnessite $\delta-\mathrm{MnO}_{2}$ for $\mathrm{Zn}$-ion aqueous batteries (Supplementary Figs. 24 and 25 and Supplementary Note 8).

Full DIES device. Full DIES device was further assembled by e$\mathrm{MoO}_{3}$ anode, graphite cathode and $2 \mathrm{M} \mathrm{LiPF}_{6}$ in ethyl methyl carbonate electrolyte to demonstrate the practical application of our $\mathrm{e}-\mathrm{MoO}_{3}$ electrode in constructing full device. As anionintercalation graphite cathode owns a high anion-intercalation potential (average discharge potential: $4.6 \mathrm{~V}$ ), a large specific capacity (396 $\mathrm{C} \mathrm{g}^{-1}$ at $50 \mathrm{~mA} \mathrm{~g}^{-1}$ ), and importantly high chargestorage kinetics (almost no capacity decay from 50 to $500 \mathrm{~mA} \mathrm{~g}^{-1}$, Supplementary Fig. 26 and Supplementary Note 9), the designed e$\mathrm{MoO}_{3} / /$ graphite device holds the opportunity to mitigate the inherent trade-off between energy density and power density for energy storage devices. According to the specific capacity of e$\mathrm{MoO}_{3}$ anode and graphite cathode at a low rate, a cathode/anode mass ratio of 2.5 was used to assemble the dual-ion-intercalation device (Fig. 4a), and a theoretical capacity of $275 \mathrm{C} \mathrm{g}^{-1}$ is expected for the cell based on the total mass of active materials. From the experiments, a reversible capacity of $200 \mathrm{C} \mathrm{g}^{-1}$ (72.7\% of theoretical capacity) could be achieved at $100 \mathrm{~mA} \mathrm{~g}^{-1}$ (based on the mass of e- $\mathrm{MoO}_{3}$ ) within a $1.0-3.5 \mathrm{~V}$ voltage range.

Figure $4 \mathrm{~b}$ shows the first four galvanostatic charge/discharge cycles using a Li metal reference electrode to record the anode and cathode potentials during the cell cycling. After the first two cycles, the potential windows for anode and cathode stabilize as $1.8-3.3$ and $4.3-5.3 \mathrm{~V}$ vs. $\mathrm{Li}^{-} \mathrm{Li}^{+}$, respectively (Fig. $4 \mathrm{~b}$ ). At the end of charge and discharge, the cathode and anode are close to its upper potential limit $\left(3.3 \mathrm{~V}\right.$ vs. $\mathrm{Li} / \mathrm{Li}^{+}$for e- $\mathrm{MoO}_{3}, 5.3 \mathrm{~V}$ vs. $\mathrm{Li} /$ $\mathrm{Li}^{+}$for graphite), respectively. The unexploited capacity (capacity 
a

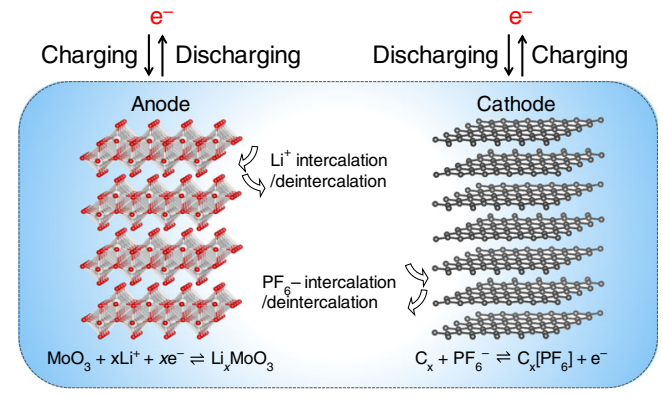

b

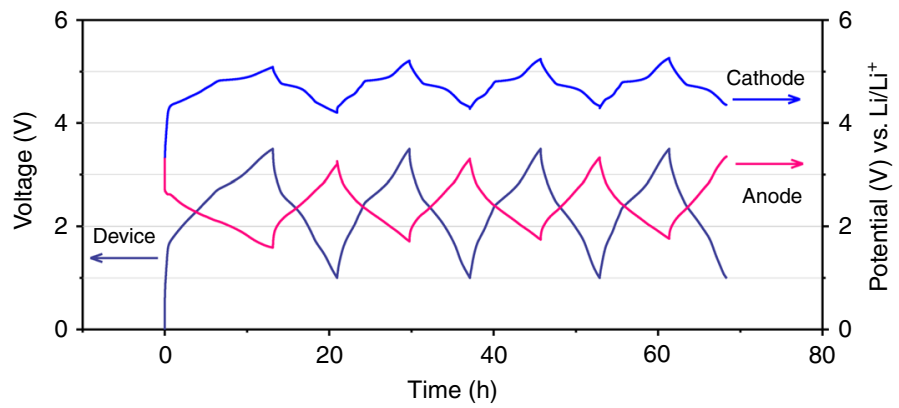

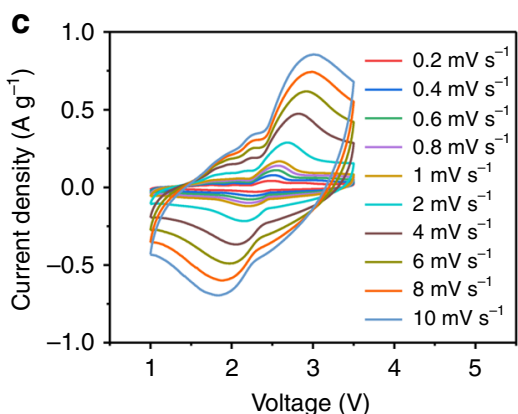

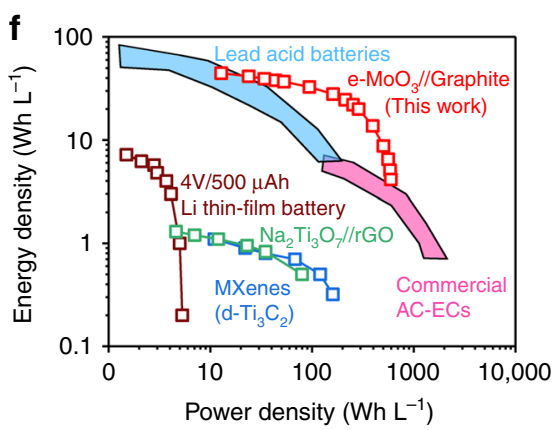

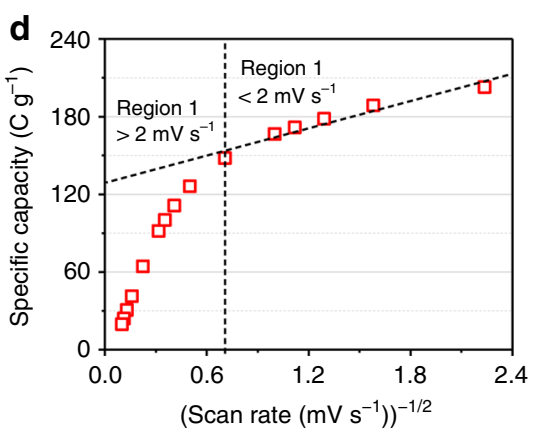
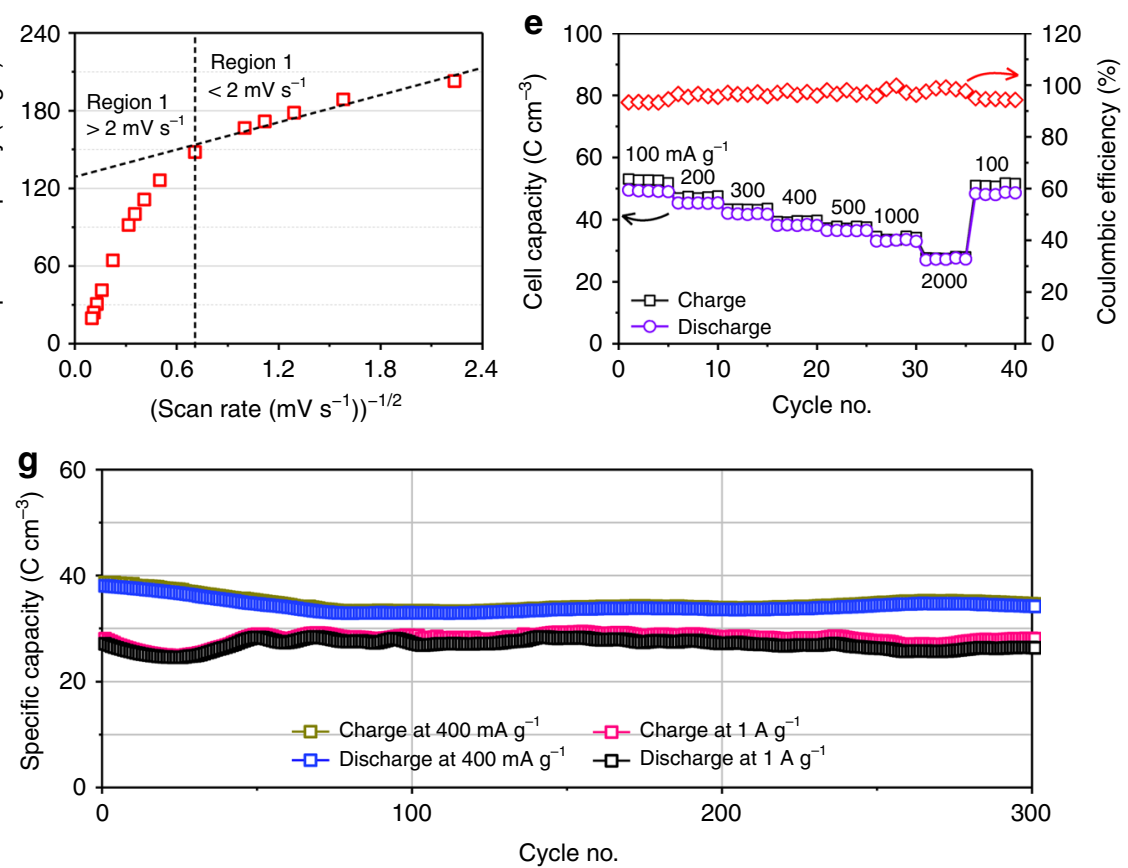

Fig. 4 e- $\mathbf{M o O}_{3} / /$ graphite DIES device. a Design of the dual-ion-intercalation $\mathrm{MoO}_{3} / /$ graphite cell. On the anode side, predominantly $\mathrm{Li}+$ is intercalated and de-intercalated between $\left[\mathrm{MoO}_{6}\right]$ layers of $\mathrm{MoO}_{3}$ during charge/discharge. On the cathode side, graphite is used as a host for hexafluorophosphate $\left(\mathrm{PF}_{6}{ }^{-}\right)$anion intercalation/de-intercalation. $\mathbf{b}$ The initial four galvanostatic charge/discharge cycles at $100 \mathrm{~mA} \mathrm{~g}^{-1}$ and the corresponding potential variation of the cathode and anode. $\mathbf{c} C V$ curves of the device at different scan rates. $\mathbf{d}$ Change of the gravimetric capacity based on the total active mass as a function of $v^{-1 / 2}$. e Rate performance of the e- $\mathrm{MoO}_{3} / /$ graphite device based on the volume of the whole device. $\mathbf{f}$ Ragone plots of e-MoO $3 / /$ graphite device in comparison with state-of-the-art electrochemical energy storage devices; the performance is normalized to the total cell volume, which includes the active materials, current collectors and separators. $g$ Cycling performance of the e- $\mathrm{MoO}_{3} / /$ graphite device at $400 \mathrm{~mA} \mathrm{~g}^{-1}$ and $1 \mathrm{Ag}^{-1}$.

at a potential $<1.8 \mathrm{~V}$ for $\mathrm{e}-\mathrm{MoO}_{3}$ and $<4.3 \mathrm{~V}$ for graphite) explains the lower capacity of the device compared with the theoretical values. Noteworthy is that the Coulombic efficiency of e- $\mathrm{MoO}_{3}$ anode (85\%) at the first cycle is close to that of graphite cathode (75\%, Supplementary Fig. 27$)$, so that the two electrodes in the full cell provide suitable buffers for each other during the initial polarization. Moreover, the anode potential is far above the Li plating potential, which can effectively prevent the safety issue associated with metal dendrite growth.

$\mathrm{CV}$ curves recorded from 0.2 to $100 \mathrm{mV} \mathrm{s}^{-1}$ (discharge time from $3.5 \mathrm{~h}$ to $25 \mathrm{~s}$ ) present multi-pairs of redox peaks, corresponding to different steps of anion and cation intercalation/de-intercalation (Fig. 4c and Supplementary Fig. 28). To establish the rate-limiting step of the charge storage process, Fig. $4 \mathrm{~d}$ plots the specific capacity based on the total active mass as a function of $v^{-1 / 237}$. At a low scan rate of $0.2 \mathrm{mV} \mathrm{s}^{-1}$, the capacity is up to $222 \mathrm{C} \mathrm{g}^{-1}$. Along with the increasing scan rate, there are two distinct regions. At scan rates $<2 \mathrm{mV} \mathrm{s}^{-1}$, the charge storage is almost not limited by the solid-state ion diffusion, thus the capacity is mostly independent on the scan rate. The extrapolated $y$-intercept capacity, that is, the charge storage from capacitive processes at the infinite scan rate, reaches around 130 $\mathrm{C} \mathrm{g}^{-1}$. The high kinetics of the device is also reflected by the slope of the plots of $\log (i)$ vs. $\log (v)$ for the main redox peaks (Supplementary Fig. 29 and Supplementary Note 10).

We further studied the rate performance of the DIES device from $100 \mathrm{~mA} \mathrm{~g}^{-1}$ to $2 \mathrm{~A} \mathrm{~g}^{-1}$ (Fig. 4e). The capacity based on the total cell stack volume (illustrated in Supplementary Fig. 30 and Supplementary Note 11$)$ reaches $49 \mathrm{C} \mathrm{cm}^{-3}\left(200 \mathrm{C} \mathrm{g}^{-1}\right.$, Supplementary Fig. 31) at $100 \mathrm{mAg}^{-1}$, and $55 \%$ capacity was maintained when the current density increased to $2 \mathrm{Ag}^{-1}$ (a discharge time of $3.2 \mathrm{~min}$ ). The Ragone plot shown in Fig. $4 \mathrm{f}$ compares the volumetric performance of the cell with the state of the art of electrochemical energy storage devices (Supplementary Fig. 32 shows the performance normalized to the active material weight). The present e- $\mathrm{MoO}_{3} / /$ graphite device could 
deliver an energy density up to $44 \mathrm{Wh} \mathrm{L}^{-1}$, which outperforms those of $\mathrm{Li}$ thin-film micro-battery ${ }^{38}$, Na-ion capacitors ${ }^{39}$, activated carbon- -40 and MXene-based ${ }^{41}$ supercapacitors, and is comparable to those of lead-acid batteries ${ }^{42}$. Meanwhile, a decent maximum power density of $600 \mathrm{~W} \mathrm{~L}^{-1}$ was achieved, close to supercapacitor-level power densities.

Finally, cycling stability was evaluated by galvanostatic charge/ discharge tests (Fig. 4g). Impressive cycling stability with $90 \%$ and $97 \%$ capacity retention was observed over 300 cycles at 400 and $1000 \mathrm{mAg}^{-1}$. Note that both the volumetric and gravimetric capacities of graphite are substantially lower than those of e- $\mathrm{MoO}_{3}$, which consequently limit the energy storage capability of the whole DIES device. Li-ion full cell was also assembled by e- $\mathrm{MoO}_{3}$ anode and commercial $\mathrm{LiCoO}_{2}$ cathode (Supplementary Fig. 33 and Supplementary Note 12). Although the maximum energy density of e- $\mathrm{MoO}_{3} / / \mathrm{LiCoO}_{2}$ device $\left(146 \mathrm{Wh} \mathrm{kg}^{-1}\right)$ is slightly higher than that of e- $\mathrm{MoO}_{3} / /$ graphite device $\left(133 \mathrm{Wh} \mathrm{kg}^{-1}\right)$, the power density of e- $\mathrm{MoO}_{3} / / \mathrm{LiCoO}$ is far below that of e- $\mathrm{MoO}_{3} / /$ graphite device. As a result, developing a new cation-intercalation cathode with comparable specific capacity with $\mathrm{e}-\mathrm{MoO}_{3}$ anode would be beneficial for further boosting the energy and power densities of full devices.

\section{Discussion}

In summary, we demonstrated an efficient $\mathrm{H}_{2} \mathrm{O}$-incorporation strategy for expanding the interlayer gaps of $\alpha-\mathrm{MoO}_{3}$, which triggers a robust $\mathrm{Li}^{+}$storage ability with significantly improved rate capability and prolonged cycling stability. There are three key advantages of our strategy. First, the incorporated $\mathrm{H}_{2} \mathrm{O}$ molecules function as effective spacers to stabilize the expanded interlayer gaps in e- $\mathrm{MoO}_{3}$, which provides efficient $\mathrm{Li}^{+}$diffusion channels and avoid the irreversible phase transition of e- $\mathrm{MoO}_{3}$ during the initial lithiation process. Second, the $\mathrm{H}_{2} \mathrm{O}$ molecules can shield electrostatic interaction between $\mathrm{Li}^{+}$and e- $\mathrm{MoO}_{3}$ lattice, thus alleviating the volume change of e- $\mathrm{MoO}_{3}$ during repeated $\mathrm{Li}$ intercalation/deintercalation and improving the cycling stability of e- $\mathrm{MoO}_{3}$. Third, since the incorporated $\mathrm{H}_{2} \mathrm{O}$ molecules take the place of lattice $\mathrm{O}$ and the molecular mass of $\mathrm{H}_{2} \mathrm{O}$ is very close to $\mathrm{O}$, the improved rate capability and cycling stability of e- $\mathrm{MoO}_{3}$ come without the sacrifice of specific capacity. Moreover, a DIES device was assembled by coupling cation-intercalation e- $\mathrm{MoO}_{3}$ and anionintercalation graphite. Such a device links the intercalation-type charge storage with fast kinetics, which thus can bring together high power density (up to $600 \mathrm{~W} \mathrm{~L}^{-1}$ ) and energy density (up to $44 \mathrm{Wh}$ $\mathrm{L}^{-1}$ ). This study offers insightful understanding of the interlayer gap-engineering strategy to improve the ion-intercalation chemistry of layered electrode materials, which opens opportunities for the next-generation energy storage technologies.

\section{Methods}

Materials. All chemicals were of analytical grade and used directly without any purification. Ammonium molybdate tetrahydrate $\left(\left(\mathrm{NH}_{4}\right)_{6} \mathrm{Mo}_{7} \mathrm{O}_{24} \cdot 4 \mathrm{H}_{2} \mathrm{O}\right)$, lithium cobalt oxide $\left(\mathrm{LiCoO}_{2}\right)$, concentrated $\mathrm{HNO}_{3}(70 \mathrm{wt} \%)$, n-butyl lithium in hexane, hexane, Li foil, graphite flakes (average size $20 \mu \mathrm{m}$ ), sodium alginate, Super $\mathrm{P}$ carbon black, and $2 \mathrm{M} \mathrm{LiPF}_{6}$ in ethyl methyl carbonate were purchased from Sigma-Aldrich.

Material preparation. $\alpha-\mathrm{MoO}_{3}$ nanowires were prepared through a hydrothermal method. In all, $6.5 \mathrm{~g}$ of $\left(\mathrm{NH}_{4}\right)_{6} \mathrm{Mo}_{7} \mathrm{O}_{24} 4 \mathrm{H}_{2} \mathrm{O}$ was first dissolved into $180 \mathrm{~mL}$ of distilled water. Then $30 \mathrm{~mL}$ concentrated $\mathrm{HNO}_{3}(70 \mathrm{wt} \%)$ was added into the solution, followed by vigorous stirring. The obtained solution was then transferred into a 250 - $\mathrm{mL}$ Teflon-lined stainless autoclave and heated in an electric oven at $180^{\circ} \mathrm{C}$ for $12 \mathrm{~h}$. After naturally cooled down to room temperature, the obtained powder sample was washed thoroughly with distilled water and dried in a vacuum oven at $80^{\circ} \mathrm{C}$ for $12 \mathrm{~h}$.

e- $\mathrm{MoO}_{3}$ was obtained by dispersing $500 \mathrm{mg}$ of $\alpha-\mathrm{MoO}_{3}$ nanowires in $16 \mathrm{~mL}$ of $0.8 \mathrm{M} \mathrm{n}$-butyl lithium in hexane. The mixture was then stirred for $24 \mathrm{~h}$ at room temperature under the protection of inert argon atmosphere. The lithiated compound was separated by vacuum filtration and washed several times with hexane. Subsequently, the sample was placed in $100 \mathrm{~mL}$ of distilled water and stirred for half an hour. Finally, the sample was centrifuged and dried in a vacuum oven at $80^{\circ} \mathrm{C}$ for $12 \mathrm{~h}$.

Electrochemical measurements. All the half-cell tests were conducted in CR2032 coin-type cells. To prepare the electrodes, active materials $\left(\alpha-\mathrm{MoO}_{3}\right.$, e$\mathrm{MoO}_{3}$, and graphite), binder (sodium alginate), and Super P carbon black were mixed with a weight ratio of $8: 1: 1$. The mixture was dispersed in water and coated on a $\mathrm{Cu}$ foil $\left(\alpha-\mathrm{MoO}_{3}, \mathrm{e}-\mathrm{MoO}_{3}\right)$ or an $\mathrm{Al}$ foil (graphite), followed by drying at $80^{\circ} \mathrm{C}$ for $12 \mathrm{~h}$ under vacuum. The loading mass of $\alpha-\mathrm{MoO}_{3}$ and e$\mathrm{MoO}_{3}$ is about $0.6 \pm 0.1 \mathrm{mg} \mathrm{cm}{ }^{-2}$, while the loading mass of graphite is $1.5 \pm$ $0.1 \mathrm{mg} \mathrm{cm}^{-2}$. The coin cells were assembled using $\mathrm{Li}$ metal foil as a counter electrode, Celgard 2400 as the separator, and $2 \mathrm{M} \mathrm{LiPF}_{6}$ dissolved in ethyl methyl carbonate as the electrolyte.

The full-cell tests were performed with a three-electrode stainless steel Swagelok cell. e- $\mathrm{MoO}_{3}$ coated on $\mathrm{Cu}$ foil and graphite coated on $\mathrm{Al}$ foil were used as anode and cathode, respectively, with a mass ratio of 1:2.5. A Li metal foil was inserted as a reference electrode to monitor the potential variation of both anode and cathode. All cell assembly was carried out in an argon-filled glove box, and the concentration of $\mathrm{O}_{2}$ and $\mathrm{H}_{2} \mathrm{O}$ were kept $<0.1 \mathrm{ppm}$.

The charge-discharge curves were collected from a Land battery test system (LAND CT2001A) at room temperature. GITT test was performed with a galvanostatic charge/discharge pulse of $50 \mathrm{~mA} \mathrm{~g}^{-1}$ for $10 \mathrm{~min}$, followed by an open circuit step for $3 \mathrm{~h}$. Both CV and electrochemical impedance measurements were conducted on a VMP3 potentiostat (Biologic, USA). The electrochemical impedance measurements were carried out at a $10 \mathrm{mV}$ ac oscillation amplitude over the frequency range of $100 \mathrm{kHz}$ to $0.01 \mathrm{~Hz}$.

Characterization. The microstructures and compositions of samples were analyzed by field-emission SEM (Carl Zeiss Gemini 500), TEM (FEI Tecnai G² F30) XRD (Bruker D8) using Cu Ka radiation $(\lambda=0.154 \mathrm{~nm})$, and TGA (Netzsch DSC204 F1). Raman spectra were measured on a NTMDT confocal spectrometer with a $532-\mathrm{nm}$ laser, and the spot size of the laser beam was $\sim 0.5 \mu \mathrm{m}$. Infrared spectra were recorded on a FT-IR Spectrometer Tensor II (Bruker) with an ATR unit. EPR measurement was performed in the $X$-band $(9.32 \mathrm{GHz})$ with $1.0 \mathrm{G}$ modulation amplitude and a magnetic field modulation of $100 \mathrm{kHz}$ using a Bruker, A300-10-12 Bruker EPR spectrometer at $90 \mathrm{~K}$.

XPS, near-edge X-ray absorption fine structure (NEXAFS), and ultraviolet photoemission spectroscopy were measured at the Photoemission Endstation (BL10B beamline) of the National Synchrotron Radiation Laboratory (NSRL) in Hefei, China. Briefly, the beamline is connected to a bending magnet and equipped with three gratings that cover photon energies from 100 to $1000 \mathrm{eV}$ with a typical photon flux of $1 \times 10^{10}$ photons/s and a resolution $(E / \Delta E)$ better than 1000 at 244 eV. XPS spectra were collected using monochromatic Mg-Ka X-ray (1254.6 eV) as the excitation source. NEXAFS spectra were recorded in the total electron yield mode using a sample current measurement.

To detect the conductivity, $10 \mathrm{mg}$ sample was first dispersed in ethanol and coated on a cellulose membrane (diameter of $4.5 \mathrm{~cm}$ ) through vacuum filtration. The membrane loaded with sample was cut into a size of $1 \times 1 \mathrm{~cm}^{2}$, and then a four-point contact was placed on the surface to define a square. The $I-V$ curves were measured in van der Pauw geometry under vacuum at varied temperatures (from 100-400 K) using a commercial Lakeshore Hall System.

A two-electrode Swagelok cell was used for in operando XRD tests.

Freestanding $\alpha-\mathrm{MoO}_{3}$ or e- $\mathrm{MoO}_{3}$ film consisting of $90 \mathrm{wt} \%$ of active material, $5 \mathrm{wt}$ $\%$ of Super P, and $5 \mathrm{wt} \%$ of polytetrafluoroethylene was placed onto a beryllium foil acting as the current collector, and a Li foil was used as the counter electrode. XRD test was carried out on a Bruker D8 advance diffractometer in the $10-50^{\circ} 2 \theta$ range with a step of $0.0152^{\circ}$, while the electrode was undergoing a galvanostatic charge/ discharge test at $50 \mathrm{~mA} \mathrm{~g}^{-1}$.

Computational details. All calculations were performed using the plane-wave DFT code available in the Vienna Ab initio Simulation Package (VASP) within the generalized gradient approximation, using the Perdew-Burke-Ernzerhof functional for the exchange and correlation potential. Spin polarized calculations were performed to account for orbit coupling. The electronic wave functions were described in the projected augmented wave formalism, and a real-space projection was further used for the total wavefunction analysis. The cutoff energy for plane-wave basis set was set to $400 \mathrm{eV}$. All atomic positions and lattice vectors were fully optimized using a conjugate gradient algorithm to obtain the unstrained configuration. Atomic relaxation was performed until the change of total energy was $<1 \times 10^{-5} \mathrm{eV}$, and all the forces on each atom were $<0.01 \mathrm{eV} \AA^{-1}$. The orthorhombic cell with space group Pbnm was used for $\alpha-\mathrm{MoO}_{3}$. Supercells containing $2 \times 1 \times 2$ conventional cells (16 formula units, Supplementary Figs. 7 and 8 ) were used to calculate energies and band structure, in which Monkhorst-Pack scheme $k$ point grid was set to $5 \times 3 \times 5$. 


\section{Data availability}

The data that support the findings of this study are available from the corresponding authors upon reasonable request.

Received: 9 December 2019; Accepted: 27 February 2020;

Published online: 12 March 2020

\section{References}

1. Simon, P., Gogotsi, Y. \& Dunn, B. Where do batteries end and supercapacitors begin? Science 343, 1210-1211 (2014).

2. Yu, M. H. \& Feng, X. L. Thin-film electrode-based supercapacitors. Joule 3, 338-360 (2019).

3. Wang, X. et al. Influences from solvents on charge storage in titanium carbide MXenes. Nat. Energy 4, 241-248 (2019).

4. Chen, C. et al. $\mathrm{Na}^{+}$intercalation pseudocapacitance in graphene-coupled titanium oxide enabling ultra-fast sodium storage and long-term cycling. Nat. Commun. 6, 6929 (2015)

5. Grey, C. P. \& Tarascon, J. M. Sustainability and in situ monitoring in battery development. Nat. Mater. 16, 45-56 (2016).

6. Salanne, M. et al. Efficient storage mechanisms for building better supercapacitors. Nat. Energy 1, 16070 (2016).

7. Yu, M. et al. Boosting the energy density of carbon-based aqueous supercapacitors by optimizing the surface charge. Angew. Chem. Int. Ed. 56, 5454-5459 (2017).

8. Wang, D. Y. et al. Advanced rechargeable aluminium ion battery with a highquality natural graphite cathode. Nat. Commun. 8, 14283 (2017).

9. Chen, C.-C. \& Maier, J. Decoupling electron and ion storage and the path from interfacial storage to artificial electrodes. Nat. Energy 3, 102-108 (2018).

10. Wang, M. \& Tang, Y. A review on the features and progress of dual-ion batteries. Adv. Energy Mater. 8, 1870088 (2018).

11. Ji, B., Zhang, F., Song, X. \& Tang, Y. A novel potassium-ion-based dual-ion battery. Adv. Mater. 29, 1700519 (2017).

12. Sheng, M. H., Zhang, F., Ji, B. F., Tong, X. F. \& Tang, Y. B. A novel tingraphite dual-ion battery based on sodium-ion electrolyte with high energy density. Adv. Energy Mater. 7, 1601963 (2017)

13. Kravchyk, K. V. et al. High-energy-density dual-ion battery for stationary storage of electricity using concentrated potassium fluorosulfonylimide. Nat. Commun. 9, 4469 (2018)

14. Wang, G. et al. Self-activating, capacitive anion intercalation enables highpower graphite cathodes. Adv. Mater. 30, e1800533 (2018).

15. Wang, G. et al. Polarity-switchable symmetric graphite batteries with high energy and high power densities. Adv. Mater. 30, e1802949 (2018).

16. Lin, M. C. et al. An ultrafast rechargeable aluminium-ion battery. Nature 520, 325-328 (2015).

17. Wang, M. et al. Reversible calcium alloying enables a practical roomtemperature rechargeable calcium-ion battery with a high discharge voltage. Nat. Chem. 10, 667-672 (2018).

18. Bellani, S. et al. $\mathrm{WS}_{2}$-graphite dual-ion batteries. Nano Lett. 18, 7155-7164 (2018).

19. Zhang, G. et al. $\alpha-\mathrm{MoO}_{3-\mathrm{x}}$ by plasma etching with improved capacity and stabilized structure for lithium storage. Nano Energy 49, 555-563 (2018).

20. Meduri, P. et al. $\mathrm{MoO}_{3-\mathrm{x}}$ nanowire arrays as stable and high-capacity anodes for lithium ion batteries. Nano Lett. 12, 1784-1788 (2012).

21. Zhou, L. et al. $\alpha-\mathrm{MoO}_{3}$ nanobelts: a high performance cathode material for lithium ion batteries. J. Phys. Chem. C 114, 21868-21872 (2010).

22. Mendoza-Sánchez, B. \& Grant, P. S. Charge storage properties of a $\alpha-\mathrm{MoO}_{3} /$ carboxyl-functionalized single-walled carbon nanotube composite electrode in a Li ion electrolyte. Electrochim. Acta 98, 294-302 (2013).

23. Wang, X.-J., Nesper, R., Villevieille, C. \& Novák, P. Ammonolyzed $\mathrm{MoO}_{3}$ nanobelts as novel cathode material of rechargeable Li-ion batteries. Adv. Energy Mater. 3, 606-614 (2013).

24. Mai, L. Q. et al. Lithiated $\mathrm{MoO}_{3}$ nanobelts with greatly improved performance for lithium batteries. Adv. Mater. 19, 3712-3716 (2007).

25. Brezesinski, T., Wang, J., Tolbert, S. H. \& Dunn, B. Ordered mesoporous alpha-MoO3 with iso-oriented nanocrystalline walls for thin-film pseudocapacitors. Nat. Mater. 9, 146-151 (2010).

26. Kim, H. S. et al. Oxygen vacancies enhance pseudocapacitive charge storage properties of $\mathrm{MoO}_{3-\mathrm{x}}$. Nat. Mater. 16, 454-460 (2017).

27. Gogotsi, Y. \& Simon, P. True performance metrics in electrochemical energy storage. Science 334, 917-918 (2011)

28. Xiong, R. et al. Infrared and EPR studies of the red potassium molybdenum bronze $\mathrm{K}_{0.33} \mathrm{MoO}_{3}$. J. Mater. Sci. 36, 5511-5514 (2001)
29. Dickens, P. G. \& Neild, D. J. Some electronic properties of the molybdenum bronzes. Trans. Faraday Soc. 64, 13-18 (1968).

30. Dinh, C.-T. et al. Multi-site electrocatalysts for hydrogen evolution in neutral media by destabilization of water molecules. Nat. Energy 4, 107-114 (2018).

31. Yu, M. et al. Dual-doped molybdenum trioxide nanowires: a bifunctional anode for fiber-shaped asymmetric supercapacitors and microbial fuel cells. Angew. Chem. Int. Ed. 55, 6762-6766 (2016).

32. Zhang, $\mathrm{H}$. et al. Extracting oxygen anions from $\mathrm{ZnMn}_{2} \mathrm{O}_{4}$ : robust cathode for flexible all-solid-state Zn-ion batteries. Energy Storage Mater. 21, 154-161 (2019).

33. Mendoza-Sánchez, B. et al. An investigation of the energy storage properties of a 2D a- $\mathrm{MoO}_{3}$-SWCNTs composite films. 2D Mater. 4, 015005 (2016).

34. Lee, H. J., Shin, J. \& Choi, J. W. Intercalated water and organic molecules for electrode materials of rechargeable batteries. Adv. Mater. 30, e1705851 (2018).

35. Kundu, D., Adams, B. D., Duffort, V., Vajargah, S. H. \& Nazar, L. F. A highcapacity and long-life aqueous rechargeable zinc battery using a metal oxide intercalation cathode. Nat. Energy 1, 16119 (2016).

36. Tsumura, T. \& Inagaki, M. Lithium insertion/extraction reaction on crystalline $\mathrm{MoO}_{3}$. Solid State Ion 104, 183-189 (1997).

37. Ardizzone, S., Fregonara, G. \& Trasatti, S. "Inner" and "outer" active surface of $\mathrm{RuO}_{2}$ electrodes. Electrochim. Acta 35, 263-267 (1990).

38. Pech, D. et al. Ultrahigh-power micrometre-sized supercapacitors based on onion-like carbon. Nat. Nanotechnol. 5, 651-654 (2010).

39. Dong, S. et al. Flexible sodium-ion pseudocapacitors based on $3 \mathrm{D} \mathrm{Na}_{2} \mathrm{Ti}_{3} \mathrm{O}_{7}$ nanosheet arrays/carbon textiles anodes. Adv. Funct. Mater. 26, 3703-3710 (2016).

40. Simon, P. \& Gogotsi, Y. Capacitive energy storage in nanostructured carbonelectrolyte systems. Acc. Chem. Res. 46, 1094-1103 (2013).

41. Lukatskaya, M. R. et al. Cation intercalation and high volumetric capacitance of two-dimensional titanium carbide. Science 341, 1502-1505 (2013).

42. Simon, P. \& Gogotsi, Y. Materials for electrochemical capacitors. Nat. Mater. 7, 845-854 (2008)

\section{Acknowledgements}

This project has received funding from the European Research Council (ERC) under the European Union's Horizon 2020 research and innovation program (grant agreement No 819698 and GrapheneCore2 785219), Deutsche Forschungsgemeinschaft (MX-OSMOPED project), and German Research Foundation (DFG) within the Cluster of Excellence. H.S., P. R., and P.S. thank the Agence Nationale de la Recherche (Label STORE-EX) for financial support. M.Y. is grateful for a scholarship from the Alexander von Humboldt Foundation. H.S. is supported by a grant from the China Scholarship Council. C.Z.W. is supported by the U.S. Department of Energy, Office of Science, Basic Energy Sciences, Division of Materials Science and Engineering, including the computer time on National Energy Research Scientific Computing Center (NERSC), under Contract No. DE-AC0207CH1 1358. The authors acknowledge the use of the facilities in the Dresden Center for Nanoanalysis at the Technische Universität Dresden and synchrotron experimental facilities of the National Synchrotron Radiation Laboratory (NSRL) in Hefei, China (BL10B beamline). The authors also thank Dr. Jian Zhang (TU Dresden), Mingchao Wang (TU Dresden), Xue Bai (CIRIMAT), and Dr. Xusheng Zheng (NSRL) for helpful discussions.

\section{Author contributions}

X.F. and M.Y. conceived the project and designed materials and experiments. M.Y. conducted material preparation and most of characterization. P.S. supervised the electrochemical investigation that M.Y. and H.S. carried out. C.-Z.W. supervised the DFT calculation that F.Y. performed. P.R. supervised the Rietveld refinements of the X-ray diffraction results that H.S. carried out. C.L. performed transmission electron microscopic measurements. X.L. and G.W. contributed to the important discussion. All authors contributed to writing the manuscript under the supervision of X.F. and P.S

\section{Competing interests}

The authors declare no competing interests.

\section{Additional information}

Supplementary information is available for this paper at https://doi.org/10.1038/s41467 020-15216-w.

Correspondence and requests for materials should be addressed to P.S. or X.F.

Peer review information Nature Communications thanks the anonymous reviewer(s) for their contribution to the peer review of this work. Peer reviewer reports are available.

Reprints and permission information is available at http://www.nature.com/reprints

Publisher's note Springer Nature remains neutral with regard to jurisdictional claims in published maps and institutional affiliations. 
(c) Open Access This article is licensed under a Creative Commons Attribution 4.0 International License, which permits use, sharing, adaptation, distribution and reproduction in any medium or format, as long as you give appropriate credit to the original author(s) and the source, provide a link to the Creative Commons license, and indicate if changes were made. The images or other third party material in this article are included in the article's Creative Commons license, unless indicated otherwise in a credit line to the material. If material is not included in the article's Creative Commons license and your intended use is not permitted by statutory regulation or exceeds the permitted use, you will need to obtain permission directly from the copyright holder. To view a copy of this license, visit http://creativecommons.org/ licenses/by/4.0/.

(C) The Author(s) 2020 